\title{
Defending Contingentism in Metaphysics
}

\author{
Kristie MILLER ${ }^{\dagger}$
}

AbSTRACT

Metaphysics is supposed to tell us about the metaphysical nature of our world: under what conditions composition occurs; how objects persist through time; whether properties are universals or tropes. It is near orthodoxy that whichever of these sorts of metaphysical claims is true is necessarily true. This paper looks at the debate between that orthodox view and a recently emerging view that claims like these are contingent, by focusing on the metaphysical debate between monists and pluralists about concrete particulars. This paper argues that we should be contingentists about monism and pluralism, and it defends contingentism against some necessitarian objections by offering an epistemology of contingent metaphysical claims.

\section{Introduction}

First-order metaphysics is supposed to tell us about the metaphysical nature of our world: under what conditions composition occurs; how objects persist through time; whether properties are universals or tropes, and so on. It is widely held that these kinds of first-order metaphysical truths are not just truths about our world, but are truths about every world: they are metaphysically necessary. By metaphysical possibility I intend to include the least restrictive sphere of genuine possibilities that does not include the merely epistemic possibilities. Thus although there might be a difference between what is logically or conceptually necessary and what is metaphysically necessary insofar as there is a difference in what grounds those modal facts, the sphere of the metaphysically possible worlds is not a proper sub-set of the sphere of logically or conceptually possible worlds.

These sorts of metaphysical claims routinely assumed to be necessary include claims about the conditions of composition, the nature of persistence, the nature of properties, the existence of abstract objects and the nature of the laws of nature (although usually not the token laws). This paper looks at the debate between the orthodox view, that such claims are necessary, and a recently emerging view that they are contingent, by focusing on a metaphysical debate that has been receiving increasing attention. This is the debate between monists and pluralists about concrete particulars. The traditional view is pluralism, the claim that, very roughly, there exist many concrete particulars. More recently, however, a small number of

\footnotetext{
${ }^{\dagger}$ School of Philosophical and Historical Inquiry and The Centre for Time, The University of Sydney, Sydney, Australia; Email: kmiller@usyd.edu.au
} 
metaphysicians (most notably Horgan 2000 and Schaffer 2007) have argued for 2 monism, the view that, very roughly, there is only one concrete particular, or only one fundamental concrete particular. Ultimately, the issue concerns how we should understand the relationship between the world and what exists at the sub-regions of that world. ${ }^{1}$ This paper defends the claim that we should be contingentists about monism and pluralism.

Section 2 offers a systematic taxonomy of the various versions of monism and pluralism, a taxonomy that allows us more clearly to see how to show that these views are necessary or, alternatively, contingent. Section 3 builds on some recent work by Gideon Rosen in trying to show that these claims are not necessary truths. In Section 4 I consider the possibility that we should embrace necessitarianism because of epistemological threats raised by contingentism. I try to show first, that the necessitarian is epistemologically no better off than the contingentist, and second, I try and offer a tentative way of making sense of how we could come to know contingent metaphysical claims by appealing to a priori necessary conditional claims. Section 5 builds on this idea by considering particular arguments for monism, and showing not only that these arguments militate in favour of contingentism, but further, that we can use them to show how a contingentist could come to know metaphysical facts. Therefore, I conclude, we should embrace contingentism.

\section{Monism and pluralism}

The special composition question, posed by van Inwagen (1990), asks under what conditions some particulars compose a further particular. That question has been answered in very different ways, ranging from compositional nihilism (the view that there are no conditions under which composition occurs) at one end of the spectrum, to unrestricted composition (the view that for any arbitrary particulars, those particulars compose something) at the other.

Until recently, parties to this debate disagreed about under what conditions some particulars compose a further particular, but they agreed on the form of the question to be answered. They agreed, at a very general level, on a particular methodology: a bottom-up methodology. This methodology seeks to answer the question of which entities exist by asking under what conditions composition occurs, where it is, often tacitly, assumed that non-fundamental compose entities are ultimately composed of fundamental simple entities. Thus the methodology

${ }^{1}$ I use the phrase 'at which it exists' and 'exists at' and their cognates as neutral between a view according to which the world occupies a region of space-time, and a view according to which it is identical to a region of space-time. 
tends to presuppose that there is a particular direction of dependence ${ }^{2}$ between the world and any particulars that wholly exist ${ }^{3}$ at the sub-regions of the world.

Consider what we might call the fundamentality question. This is the question of whether the world is fundamental, and any particulars that exist at sub-regions of the world as non-fundamental ${ }^{4}$ proper parts of the world, or whether the 5 particulars that exist at sub-regions of the world are fundamental, and anything composed of those particulars as non-fundamental. The bottom-up methodology 6 does not entail, but fits very nicely with, a particular answer to the fundamentality question, namely one that takes proper parts of the world to be fundamental, and the world to be non-fundamental. ${ }^{5}$ We might think of this view of fundamentality as also a bottom-up view according to which fundamentality relations hold from the bottom up, and the bottom level of ontology is the most fundamental. The view that most naturally follows from this view is that at bottom there are fundamental building blocks - simples - from which everything else non-fundamental is composed. Call this view pluralism. ${ }^{6}$

An alternative methodology, which has recently become popular, is top-down. This methodology asks under what conditions the world decomposes into parts. This methodology does not entail, but fits nicely with, a quite different answer to the fundamentality question according to which fundamentality relations are topdown. That is, the world is considered to be fundamental, and any of its parts merely derivative. According to this view then, there exists a fundamental world, and we ask under what conditions the world decomposes into non-fundamental proper parts. ${ }^{7}$ This view is monism. ${ }^{8}$

${ }^{2}$ I borrow the notion of dependence from Schaffer (unpublished, p. 6). For Schaffer, dependence is a synchronic ordering relation - it is reflexive, anti-symmetric, and transitive - that entails that the dependent supervenes upon that upon which it depends. The direction of dependence is determined by an asymmetry-maker, in this case the parthood related, which yields a mereological hierarchy and hence a hierarchy of dependence.

3 Of course, the world exists at all of its sub-regions. The issue is which other particulars exist; that is, for each sub-region of the world, is there some particular that exists at just that sub-region. I will say that a particular $P$ wholly exists at a region $R$ iff for every sub-region $R^{*}$ of $R, P$ exists at $R^{*}$, and there is no region R\# that is discrete from $R$, such that $P$ exists at $R \#$.

${ }^{4}$ Or derivative, to use Schaffer's term (unpublished, p. 5).

${ }^{5}$ Where fundamentality is understood in terms of dependence. The proper parts of the world are fundamental and the world non-fundamental just in case the world depends on the proper parts.

${ }^{6}$ I borrow this terminology from Sider (2007) and Schaffer (2007).

7 It might be that this involves the general view that the part/whole relation is a dependence relation in which the part is dependent on the whole. Or it might be that it involves only the weaker claim that there is a dependence relation between the world and its parts, such that the world is fundamental and the parts are non-fundamental. This latter would leave it open that the direction of dependence between some of the proper parts of the world and their parts might be the reverse: the parts of proper-parts of the world might be more fundamental than the proper parts themselves.

${ }^{8}$ I borrow this term from Schaffer (2007) and Sider (2007). 
Monists and pluralists answer the fundamentality question differently. The former hold that the world is fundamental; the latter hold that some proper parts of the world are fundamental. Now consider what we might call the ontological question, the question of which non-fundamental concrete particulars exist. Pluralists think that this question should be answered by appeal to the special composition question. Non-fundamental composite particulars exist just where some plurality of simples meet the conditions under which composition occurs ${ }^{9}$ Monists think that this question should be answered by appeal to the special decomposition question (if you will), which asks under what conditions some whole - the world - decomposes into particulars. Non-fundamental particulars exist just when the conditions are met under which decomposition occurs.

There are three possible answers to the special composition question, and three possible answers to the special decomposition question. These are the same three answers: composition/decomposition occurs always, sometimes, or never. Call the view that composition/decomposition never occurs nihilism. ${ }^{10}$ Call the view that composition/decomposition occurs under only some circumstances restrictivism. ${ }^{11}$ And call the view that composition/decomposition occurs under all circumstances universalism. ${ }^{12}$ Nihilism, restrictivism and universalism offer three different answers to the ontological question. When we combine different answers to the fundamentality question with different answers to the ontological question, we get six distinct metaphysical views. Call each of these views a complete metaphysical account, or CMA. ${ }^{13}$

Then, for any world $w$ such that we can decompose $w$ into multiple disjoint regions each of which is occupied by some particular, ${ }^{14}$ nihilistic monism is true in $w$ just in case in $w$ there exists just one fundamental simple particular, the world. (Although the world is a simple, it can nevertheless be a structurally complex spatio-temporally extended simple. ${ }^{15}$ Universalist monism is true in $w$ just in case for any occupied sub-region in $w$ there is some non-fundamental proper part of $w$ particulars

${ }^{9}$ Henceforth when I talk of which particulars exist, I intend to refer only to concrete

${ }^{10}$ See for instance Unger (1979).

${ }^{11}$ See for instance van Inwagen (1990); Merricks (2001); McCall (1994). Heller (1990).

2 See for instance Lewis (1986, pp. 212-213); Sider (2001); Schaffer (unpublished);

${ }^{13}$ I do not intend to suggest that these six CMAs are exhaustive. It could be that there are no fundamentality relations at all, or at least that the world and the simples in it are equally fundamental. But dividing the terrain in this way is helpful, and it is these six CMAs in which I am interested.

${ }^{14}$ Where disjoint regions $\mathrm{R}_{1}$ and $\mathrm{R}_{2}$ can each be occupied, without us presupposing that there are two distinct particulars, one of which occupies R1 and the other R2: it could be that R1 and $\mathrm{R} 2$ are both occupied by the very same particular.

${ }^{15}$ This is the view defended by Horgan and Potrč (2000) and which they call blobjectivism, and it is the view that Schaffer (2007) calls existence monism. 
that wholly exists ${ }^{16}$ at that region. ${ }^{17}$ Restrictivist monism is true in $w$ just in case for 8 some and only some occupied sub-regions of $w$ there are particulars that wholly exist at those sub-regions and these particulars are non-fundamental proper parts of $w$. Nihilistic pluralism is true in $w$ just in case every occupied region in $w$ can be decomposed into a plurality of simple fundamental particulars, and those simple particulars do not compose any composite objects. ${ }^{18}$ Universalist pluralism is true in $w$ just in case every occupied region in $w$ can be decomposed into a plurality of fundamental particulars, such that for any arbitrary set of those particulars there is a non-fundamental particular that those particulars compose. ${ }^{19}$ Finally, restrictivist pluralism is true in $w$ just in case every occupied region in $w$ can be decomposed into a plurality of fundamental particulars, such that for some and only some of those particulars there is a non-fundamental particular that those particulars compose. ${ }^{20}$

The claim that the CMAs are modally necessary should then be interpreted as the claim that, for every world in the set of worlds $W$ such that we can decompose each of the worlds in $W$ into multiple disjoint regions each of which is occupied by some particular, the very same CMA is true at each of those worlds. ${ }^{21}$ The idea is 10 that we are only interested in worlds in the $W$ set because these are the only worlds in which it makes sense to ask which CMA is true: worlds, for instance, in which there is just a single point-sized object are ones in which the issue of composition and fundamentality does not arise.

For the purposes of this paper I will largely set aside restrictivist monism and restrictivist pluralism, since I think the strongest case for necessitarianism can be made by considering universalist and nihilist versions of monism and pluralism. I am doubtful that any account that restricts composition in a precise and nonarbitrary manner can at the same time admit into our ontology largely the objects restrictivists tend to want to admit, and less likely that this will be so in other 11 possible worlds. Anyway it is sufficient to vindicate contingentism to show that universalist and nihilist versions of monism and pluralism are best thought of as contingent, without considering any other CMAs.

\footnotetext{
${ }^{16}$ Where a particular $\mathrm{P}$ wholly exists a sub-region $\mathrm{R}$ just in case none of $\mathrm{P}$ occupies any region that is not a part of $\mathrm{R}$ and every part of $\mathrm{R}$ is occupied by $\mathrm{P}$.

${ }^{17}$ This is the view defended by Schaffer (2007 and unpublished), which he calls priority monism.

${ }^{18}$ This is the view sometimes known as nihilism, or compositional nihilism, and defended by Unger (1979).

${ }_{19}$ This is the view known as universalism, mereological universalism or unrestricted composition and defended by, for instance, Sider (2001), Lewis (1986) and Quine (1963).

${ }^{20}$ This is the view defended by, for instance, Merricks (2000) and van Inwagen (1990). 9

${ }^{21}$ See Schaffer (unpublished); van Inwagen (1990); Sider (2001); Markosian (2007). For a rare alternative view see Parsons (unpublished) and Cameron (forthcoming).
} 
Since each CMA is the conjunction of two claims, one regarding which account of fundamentality is true - monism or pluralism - and the other regarding which account of composition or decomposition is true - nihilism, restrictivism or universalism - necessitarianism is the conjunction of two claims.

Claim 1: Either monism is necessarily true or pluralism is necessarily true. ${ }^{22}$

Claim 2: If monism is true, then the correct answer to the special decomposition question is a necessary truth, and if pluralism is true, then the correct answer to the special composition question is a necessary truth. ${ }^{23}$

If either Claim 1 or Claim 2 is false, then necessitarianism is false. This paper seeks only to establish that there is good reason to suppose that at least one of Claim 1 or Claim 2 is false, and hence good reason to embrace contingentism.

\section{General arguments for contingentism}

Gideon Rosen (2006) has argued compellingly that there is a large range of metaphysical theses that make substantial ontological claims about our and other worlds that are plausibly neither conceptual nor logical truths, nor a posteriori Kripkean necessities. For instance, although certain axioms of mereology might be conceptual truths that tell us what it is to be a part, or to be a whole composed of parts, the axioms that tell us which mereological composites exist are not conceptual claims of this kind. One could perfectly well understand the parthood relation without endorsing unrestricted mereological composition. Rosen suggests that these latter sorts of axioms should be thought of as conditionals such as: given that there are mereological aggregates, then for any xs, those xs compose a y. But that conditional does not guarantee that every world is one in which there are mereological aggregates. The strategy is not unfamiliar. Hartry Field agrees with Hale and Wright that if there are numbers, then Hume's Principle (the number of Fs equals the number of Gs just in case there the Fs and the Gs are equinumerous) is true. He merely disagrees with Hale and Wright that as stated Hume's principle is a conceptual truth that guarantees the existence of necessarily existing mathematical objects (see Field 1993; Hale and Wright 1992).

The claims made by monists and pluralists are clearly of the sort that Rosen has in mind. Indeed, one of the claims that make up each of the CMAs is a claim about composition that precisely involves whether or not unrestricted mereological composition is a necessary truth or not. Rosen's suggestion that these axioms only

${ }^{22}$ This presupposes the monism and pluralism are exhaustive. I think that is a plausible assumption. More importantly, dialectically the assumption aids the necessitarian, since it means that showing that one of these views is necessarily false entails that the other view is necessarily true, and hence is sufficient to show that necessitarianism is true.

${ }^{23}$ Or more simply, Claim 2: The correct answer to the special composition/ decomposition question is a necessary truth. 
express conceptual truths when interpreted as conditionals seems right. The appropriate conditional is not, I think, the one that Rosen suggests since that would rule out restricted composition as a mereological claim. Rather, given that there are, unrestrictedly, mereological aggregates, then for any xs, those xs compose a y. Given that there are some mereological aggregates, then for some xs, those xs compose a y. Given that there are no composites, for any xs, those xs do not compose a y. Everyone can agree that these conditionals are conceptual truths. Since it does not seem to be a conceptual truth that the antecedents hold in every world, we have reason to suppose that none of the compositional claims of monism and pluralism is a conceptual truth.

Such metaphysical claims also seem to be poor candidates to be Kripkean $a$ posteriori necessities. A posteriori necessities frequently occur when a term functions as a rigid designator. Some metaphysical claims of the kind Rosen has in mind might turn out to be a posteriori necessities. It is at least not obviously crazy for Armstrong and Heathcote (1991) to assert that it is an a posteriori necessity that causation involves a relation of nomic necessitation between the properties that are the causal relata. Similarly, one can imagine a range of metaphysical claims about the nature of space-time that might be a posteriori necessities. Perhaps if actually space-time is substantival, then relationist worlds are worlds that, as a matter of a posteriori necessity, lack space-time. Perhaps if our world is one in which there are relations of nomic necessitation, then worlds without such relations are worlds without laws of nature as a matter of a posteriori necessity.

But none of the CMAs look like they will be a posteriori necessary. It is certainly counterintuitive that any of the relevant terms have a descriptive content that includes a rigid component, ${ }^{24}$ or that the extensions of these terms are properties, relations, or mass nouns with which we are causally connected in the way that the direct reference theorist thinks that we are, say, causally connected to water samples. ${ }^{25} \mathrm{It}$ is hard to imagine, for instance, that if we discovered that in our world unrestricted mereological composition holds, that we would conclude that composition is whatever composition relation obtains actually, where the actual relation is defined in terms of the relevant set of mereological axioms. That would be the discovery that it is a posteriori necessary that unrestricted composition holds. Yet it seems implausible that in a counterfactual world $w$ in which there exist simples but only some mereological 'composites' that we should conclude not that $w$ is a world with restricted composition, but rather a world with schmoposition, 14

${ }^{24}$ As would be the case on a largely descriptivist account of rigid designation. In that case we hold that part of the descriptive content - the part to which we have access a priori - is that the term refers, in all worlds, to whatever it refers to actually. See Chalmers (2004) and Jackson $(1998,2004)$.

${ }^{25}$ See for instance Block and Stalnaker (1999). 
since composition rigidly picks out the relation defined to include the axiom: for any xs, those xs compose a y. Composition just does not seem to be that kind of relation. ${ }^{26}$

As Rosen would put it, we should think that a proposition $\mathrm{P}$ is possible just in 15 case $\mathrm{P}$ is correctly conceivable, where $\mathrm{P}$ is correctly conceivable just in case $\mathrm{P}$ does not entail a logical inconsistency when combined with a full specification of the natures of the kinds it concerns. Thus in the case of obvious conceptual truths, it is not possible to correctly conceive that those truths are not true. But correct conceivability is supposed to guarantee that, given that we specify all the relevant natures of the things involved, we cannot correctly conceive as being false what is 16 a posteriori necessary. Thus the idea is that we cannot correctly conceive of water's being other than $\mathrm{H}_{2} \mathrm{O}$ given that it is $\mathrm{H}_{2} \mathrm{O}$, because this is not logically consistent with its being the essential nature of water to be whatever it is actually. Whenever we are considering claims about water, a full specification of the relevant intrinsic properties will include a specification that actually water is $\mathrm{H}_{2} \mathrm{O}$, and will tell us what the chemical composition is of any watery substances we are considering counterfactually.

The idea is that this procedure avoids modal error. Prima facie, though, it is not clear that it avoids modal error altogether. Notoriously, there are those who claim that we can correctly conceive of zombie worlds, worlds that are minimal physical duplicates of the actual world, but which lack phenomenal character (Chalmers 1996). Since physicalism just is the claim that necessarily, any minimal physical duplicate of our world is a duplicate simpliciter, such correct conceiving would entail the truth of dualism. The problem is that even avowed physicalists often find themselves able to conceive of the zombie world, while being convinced that physicalism is true. They, then, must contend that correct conceiving has led them astray: such a world is not possible.

The most plausible hypothesis advanced by physicalists to explain their apparently being able to conceive of the zombie world is that there is something pertinent that we do not know: either we do not know some facts about the entailment of the phenomenal from the physical, or we do not know some physical facts. We are required to correctly conceive of the entire physical nature of a world being reproduced sans phenomenal character. But there is much about the nature of that world that we do not know, so it is not surprising that we think we can conceive of the physical facts without the phenomenal facts. Whether this is a compelling response, given that the physicalist cannot tell us what sorts of facts are the ones that we do not know, is debatable and not of concern here. The point is just that the response is entirely consistent with the methodology of correct

\footnotetext{
${ }^{26}$ Although see Williams (2006) for an alternative view.
} 
conceivability since they appeal to the existence of facts - internal natures or 17 relevant facts - which if we knew them, would render the zombie world not correctly conceivable.

Moreover, although many physicalists think that the phenomenal facts are entailed by the physical facts in our world, they allow that there could be nonphysical worlds. Necessitarians, however, think that metaphysical claims hold in every world, and so in some good sense they do not think that the distribution of matters of fact substantively entails the metaphysical truths (although it does so trivially). Given this, we might think that the methodology is on even firmer footing with respect to metaphysical claims, since, unlike in the case of the zombie world, it is unclear what sort of non-metaphysical matters of fact we could be ignorant of that would lead us to think that a particular metaphysical thesis is correctly conceivable when in fact it is not.

\section{Necessitarians fight back}

The quick route to contingentism about the CMAs, then, is to note that each seems to be correctly conceivable, and leave it at that. Since it is standard to presuppose that these views are necessary truths, however, it is worth considering on what grounds necessitarians might reject contingentism.

\subsection{Metaphysical claims as conceptual truths}

One suggestion is that we have dismissed too soon the notion that the metaphysical claims in question are conceptual truths. One strategy is to show that they are; the other is to show that we have no good reason to think that they are not. Consider the second of these strategies first. One might accept that correct conceivability is a guide to possibility, but be sceptical of our ability to correctly conceive. Perhaps we lack a sufficiently good grasp of our own concepts to know if we are correctly conceiving some proposition obtaining at a world. We can imagine a case in which, even if we know all of the relevant facts about the essences of the entities involved, we might still think that we can correctly conceive of water as being other than $\mathrm{H}_{2} \mathrm{O}$. Some of these cases are explained by our having failed to interrogate our concept sufficiently rigorously. So, for instance, although we know all the relevant facts about actual and counterfactual worlds, what we don't yet know is that our concept of water is rigid; we might mistakenly think it is merely functional. This is not very worrying. But there is a further worry in the background, which is that one might think that the true concept being deployed is the one that would in fact guide what we say given various discoveries about the actual nature of water and the intrinsic properties of other counterfactual watery substances. But we might be wrong about that even after a great deal of interrogation of our concept. For what we think we would do, what we think our dispositions will be, might turn out to be 
different from what they in fact will be. I think that there is a genuine danger that 18 sometimes we might be wrong about our concepts. I am not at all sure that if we discovered that a large percentage of the Pacific Ocean was actually not $\mathrm{H}_{2} \mathrm{O}$ but some entirely different molecule that reacts like water in almost all situations, that we wouldn't say that water is a disjunction of those two substances, or that it picks out any property that plays the water role and nothing that does not, whether that stuff is $\mathrm{H}_{2} \mathrm{O}$ or not. But I would be very surprised if these kinds of mistakes were occurring in metaphysical debates like that between the monist and the pluralist. It is hard to see what I could discover about my concept of composition, or fundamentality, that would lead me to realize that what seems to be correctly conceivable in fact turns out not to be.

The second strategy involves bolstering the claim that the metaphysical theses in question are conceptual truths. The intuition that they are not conceptually necessary truths issues both from the fact that it in no way seems to follow from our concepts of any of the metaphysical terms that the metaphysical theses are necessary, and from the fact that we seem to be able to correctly conceive of worlds in which those theses do not hold. This makes it sound as though our expectation is that we examine a single concept to determine whether there is conceptual necessity where in fact we are evaluating whole metaphysical views, not individual concepts.

Thus we might re-conceptualize the project of a priori reasoning in a way that is more consistent with recent proponents of conceptual analysis. According to 19 these views, a priori reasoning involves fitting together many interrelated concepts. We determine what is conceptually necessary by determining what is the best, most elegant systematization of our concepts (see for instance Jackson 1998). We are faced with a number of rival metaphysical packages. There are competing packages within a particular domain in metaphysics - sub-packages - and there are complete metaphysical packages, packages, which, if true, completely describe the metaphysics of our world. The kind of reasoning engaged in by metaphysicians can best be thought of as a way of determining which sub-packages are most coherent: which fit best with our folk intuitions; which make most sense of the phenomena to be explained; which give us the most explanatory power; which fit best with other metaphysical packages and so on until ultimately at the end of investigation, after reflective equilibration, we are in a position to determine which is the preferable complete metaphysical package. The complete metaphysical package that we converge on after this investigation is conceptually necessary, for the process of determining which complete package to adopt just is the process of determining which complete package is conceptually necessary. Since we are nowhere near being in a position to choose a complete metaphysical package, we should not be surprised if individual competing sub-packages can each appear to be correctly conceivable. 
Perhaps it is mere foot-stamping to note that this does not seem to ring true. Anti-Humeans and Humeans adopt very different metaphysical sub-packages across a wide range of domains. But, at least at this stage of investigation, it is hard to see that the Humean will find the anti-Humean's view conceptually necessarily false. She will think it ontologically inflationary and objectionable in a whole host of ways. But not, surely, conceptually incoherent.

It seems to me that the process described above is not the process of arriving at a conceptual truth. It is a process that involves thinking about our concepts, and considering how different metaphysical views make sense of those concepts and make sense of our world and explain various phenomena. It is an a priori process that at times appeals to conceptual analysis, or to facts about our concepts. But it is not, for all that, a process that yields conceptual truths in any ordinary sense: it does not yield truths such that, at the end of inquiry, we find competing claims incoherent. Rather, this process is really one of a priori reflec- 20 tion designed to tell us which metaphysical account is a 'best fit'. That is consistent with the metaphysical truths being synthetic a priori truths rather than conceptually necessary truths, albeit that some of the a priori data involve reflection on our concepts.

At least, if the proponent of this view really intends that the view that is converged upon is conceptually necessary, more needs to be said about why we should expect convergence, and why nothing like 'proto' conceptual incoherence is so far apparent in our investigation (that is, why so far into our investigation we 21 cannot even begin to see what it is about alternative metaphysical claims that might ultimately lead us to say that they are incoherent). Without saying more, such an account makes it too easy for the necessitarian. Suppose that after considerable reflection there is no convergence on a particular CMA. Then it is always open to the necessitarian to claim that the end of inquiry has not been reached. After all, how does one determine where the end of inquiry is? It cannot be defined in terms of convergence, for then it will be impossible to show, of some metaphysical claim, that it is not conceptually necessary. The necessitarian needs to say something more about convergence if her view is not to come out as trivial in virtue of being true no matter what we discover.

We might appeal to intuition to tell us, roughly speaking, where we are in the inquiry process. Then we might say that if we think that we are near the end of inquiry, and it does not appear that reflective equilibration will yield convergence, we should conclude that the views under consideration are not conceptually necessary unless we have some view about how reflection will ultimately lead to convergence and some reason to think that whatever we converge upon really will be conceptually necessary. No such story is forthcoming in the cases under consideration. So the necessitarian ought not to pin her hopes on the claim that the CMAs are conceptually necessary. 


\subsection{Metaphysical claims as synthetic a priori truths}

We might nevertheless think that, roughly, the process just described is the correct one. But we might instead view it as yielding synthetic a priori rather than conceptual truths. It seems to me that what lies behind this idea is that when we have competing metaphysical packages, such as the CMAs, that are empirically equivalent, all there is to metaphysical discovery is this process of equilibration and conceptual stock-taking. Let us call the metaphysical package that is preferable, after ideal reflection given the various constraints listed above, the more virtuous package. Then if we have reason to think that the very same a priori reasoning holds true in every world - which is really to say that the same CMA will be more virtuous in every world - then we have reason to think that whichever CMA is true, is necessarily true.

We can then explain why correct conception is not always a good guide to possibility. For it seems likely that we can correctly conceive that, say, pluralism is true at a world, even though monism is necessary, since it turns out that monism is more virtuous at every world.

Now, in general it does not look very plausible to move from the claim that, from the perspective of the agents in any world $w$, there is a particular form of $a$ priori reasoning $R$, such that in $w$ the agents should conclude $P$, to the conclusion that necessarily $P$. After all, a priori reasoning is not infallible reasoning: agents in two different worlds might have the same a priori reasons to believe $P$, yet $P$ might only be true in one of those worlds. My reasons for thinking I am not a brain in a vat are a priori, but a brain in a vat has the very same reasons, it is just that in her world, her a priori reasons lead her astray. So unless we have already ruled out contingentism, the fact that the same a priori reasoning would lead agents in different worlds to each conclude that the very same CMA is true at each of their worlds is no evidence that that claim is necessarily true. If contingentism is true, some of those agents simply turn out to live in sceptical worlds.

Perhaps, though, the idea is that all there is to a metaphysical claim's being true at a world is that it is the most virtuous. Then if a priori reflection tells us that that package will be more virtuous in every world, then that just is the discovery that that claim is necessarily true. The kind of equilibrative a priori process of discovering virtue, on the one hand, and the discovery of metaphysical truth, on the other, cannot come apart. So there can be no sceptical worlds.

Is this the view that metaphysical debates are merely semantic, rather than reflecting genuine metaphysical differences between the theories? ${ }^{27}$ In part that depends on what one thinks it would take for there to be genuine metaphysical differences. One might say that there are genuine differences just if there is a fact

${ }^{27}$ For views such as these see Hirsch (2002); Carnap (1932); Putnam $(1987,1988)$ and Yablo (1998). For an account of when theories are equivalent see Miller (2005). 
of the matter, a truth-maker if you will, that grounds the truth of only one CMA in any world. According to the view under consideration, a CMA is true at a world just in case ideal reflection reveals that it is more virtuous than every other CMA. This is consistent with a number of different views about the truth-maker of a CMA. One might think, for instance, that there are objective theoretical virtues, and that it is constitutive of being a theoretical virtue that that virtue tracks truth. So if a theory is more virtuous in every world then it follows that it is necessarily true. When we discover, a priori, which is more virtuous we thereby discover which is necessarily true, but we are discovering a perfectly objective metaphysical fact. On this view, there is some metaphysical fact, F, in virtue of which a particular CMA is true at a world, but the presence of $\mathrm{F}$ at a world is necessarily linked to the CMA being more virtuous at that world. Another alternative embraces the idea that there are objective theoretical virtues, but holds that what it is for a metaphysical claim of this sort to be true just is for it to be more virtuous: virtue is constitutive of truth. There are objective facts about virtue, and hence objective facts about which CMA is true at a world so long as one CMA is uniquely more virtuous, but that fact just lies in whether that CMA is more virtuous or not at that world. Finally, one might embrace the idea that virtue is constitutive of truth, but hold a more psychologistic view of virtue, according to which virtue depends on 22 various properties of humans as knowers: which theory is more virtuous depends on our particular explanatory needs given our mental capacities and our concepts. Then there are objective facts regarding theory virtue, but these facts depend on our interests. So if a particular CMA is more virtuous in every world, it is true in every world and hence necessary; although, had it been that we had different 23 explanatory interests, or slightly different mental capacities, it would have been that some other CMA was true and, perhaps, necessarily so.

In all three of these cases there is a truth-maker at each world in virtue of which a particular CMA is true. Set aside the first case for a moment. In the second case the truth-maker is the existence of some objective virtue of the theory in each world, which constitutes its truth. In the third case the truth-maker is the existence of some objective, but agent-relative, virtue of the theory in each world, which constitutes its truth. Suffice to say, these are pretty deflationary views about the nature of truth-makers for metaphysical claims. In some good sense the third option does seem to render metaphysical disputes, if not merely semantic, then at least not really genuine either. What determines whether monism or pluralism is 24] true is not whether or not the world or its sub-parts are more fundamental, or under what conditions composition occurs, but, rather, which of these claims makes most sense to us and is most useful. In a sense, the concept of a theoretical virtue turns out to be a rigid one, such that, whatever features of a theory make it more explanatory given our actual psychological properties, necessarily those features are the virtues. If a unique CMA has those virtues in every world, it is necessarily 
true. When we seem to conceive that some other CMA is possible, we are not correctly conceiving a counterfactual world in which that CMA is true; rather, we are correctly conceiving of a possible world as actual, in which our explanatory purposes and psychological properties are a particular way (a way that is different from the way they are in fact) such that given those purposes the CMA in question is more virtuous and necessarily so. That is to do no more than note that if actually water is $\mathrm{XYZ}$ and not $\mathrm{H}_{2} \mathrm{O}$, then, necessarily, water is $\mathrm{XYZ}$. The problem with this option is that it is just far too deflationary for most metaphysicians' tastes. Even if we embrace this option, it in no way follows, as we will see shortly, that any of the CMAs are necessary, for it is an open question indeed whether any unique CMA is more virtuous in every world. So this view is consistent with contingentism and we might well have reason to think that, if it were true, contingentism would follow.

Of course, as I noted earlier, if one thinks that there is a necessary connection between virtue and truth, and that we gain access to a priori synthetic truths, then one does not need to provide an account that explains why what seems to be correctly conceivable is really not conceivable. Rather, one can reject the notion that what is correctly conceivable is possible. The defender of the second option, who thinks that non-agent relative virtues constitute the truth of metaphysical claims, will reject correct conceivability for such claims. Again, I think this view is too deflationary - how can it be that the metaphysical truth depends on the convergence of agents - but more importantly I note that it need not push us towards necessitarianism for the very same reasons as those given with respect to the third option just discussed.

The first option is the least deflationary, and, to that end, probably the most amendable to the metaphysician. On this view, there is a necessary connection between the truth of a theory and its being virtuous. The virtues track truth but do not constitute it. This entails that if a CMA is more virtuous in every world, then it is necessarily true. But now it is not obvious why we should suppose that the process of reflection and equilibration described earlier is a process that tracks the real virtues. It is constitutive of the virtues that they track truth. But why think that the kind of a priori reasoning we engage in yields virtues in this sense. Although we have closed the gap between truth and virtue, we have opened up a gap between the results of ideal a priori reflection on the one hand, and objective virtue on the other. We have few reasons to suppose that the things we call virtues are necessarily linked to truth. ${ }^{28}$

${ }^{28}$ Cameron (forthcoming) makes the suggestion that we deny that if there is a CMA that is more theoretically virtuous in every world than its competitors, that is reason to think it is necessarily true. This suggestion differs in that it takes it as constitutive of the real virtues that they lead to truth, but suggests that the proto-virtues might not be the actual virtues. 
Even setting aside that worry, there is every possibility that after ideal a priori reflection we will discover that different CMAs are differently virtuous in different worlds. For simplicity, let us focus just on the 'traditional' theoretical virtues (which arguably do not include various features that the virtues, in the sense in which I have been using the term, will include, such as how well a metaphysical package systematizes our concepts or makes sense of our folk theories, or fits with other metaphysical packages and so forth) to get a flavour for why this might be so. Even if for every theoretical virtue, $T$, there is a unique CMA that is more virtuous with respect to $T$ than any other CMA, it does not follow that there is a unique CMA that is more theoretically virtuous simpliciter than any other. Consider the virtue of ontological parsimony. We might be tempted to say that nihilistic monism is the most ontologically parsimonious account since it posits the fewest entities. On the other hand, nihilistic monism posits more relations than other CMAs. Nihilist monists hold that there is no coffee table in what I would call my living room. But the world does instantiate a particular property at a particular location. It has the property of being, as we might say, 'coffee-table-esque' at a location. In order to be able to talk about the properties of the world at locations without positing the existence of objects at those locations, the nihilist monist needs to introduce a set of new relations: adverbialized instantiation relations. ${ }^{29}$ The details of this proposal are incidental, but roughly the idea is that the world instantiates properties like being coffee-table-esque in a 'regional' manner and that does not commit one to the existence of a coffee table. If these relations are part of ontology, then nihilist monism is probably not more ontologically parsimonious than the other CMAs. If they are not part of ontology, then nihilist monism is more ontologically parsimonious than rival views, but it is less simple. So what it gains with respect to one virtue, it loses with respect to another. Indeed, it looks prima facie plausible that this will generally be the case: what one CMA loses with respect to certain virtues, it makes up with respect to others.

There are two ways in which theories can be equally theoretically virtuous. They can be what we might call strongly equally virtuous, where two theories $T_{1}$ and $T_{2}$ are strongly equally virtuous iff for every theoretical virtue $V, T_{1}$ has $V$ to the same degree as $T_{2}$. Or they can be weakly equally virtuous, where two theories $T_{1}$ and $T_{2}$ are weakly equally virtuous iff there are theoretical virtues $V 1 \ldots V n$, such that $T_{1}$ has each $V i$ to a different degree than $T_{2}$, but the average degree of theoretical virtue of $T_{1}$ is the same as the average degree of virtue of $T_{2}$. That is, one is tempted to say that the virtues even out, so that the total 'virtuousness package' is the same for each theory. Given that the a priori process of reflection in question

29 These relations are analogous to the kind of temporally adverbialized instantiation relations to which endurantists about persistence appeal when they say, for instance, that an object has a property $\mathrm{P}$ in a $\mathrm{t}_{1} \mathrm{ly}$ manner, and lacks $\mathrm{P}$ in a $\mathrm{t}_{2} \mathrm{ly}$ manner. 
is really interested in the total virtuousness package of metaphysical theories, it could well be that this process would yield the conclusion that at least some of the CMAs are weakly equally virtuous and therefore equally virtuous in the relevant sense. In that case, ideal a priori reflection would yield a contingentist conclusion: different CMAs are true in different worlds. ${ }^{30}$

Now what I have said here does not settle the matter. I have not shown that at least some of the CMAs are equally virtuous across worlds. But neither has the necessitarian shown that a unique CMA is the most virtuous across worlds. Nor, I think, do the prospects for the necessitarian seem that good. Here is a proposal that would make a necessitarian conclusion more likely: it turns out that ontological parsimony always trumps simplicity. ${ }^{31}$ Then nihilistic monism is always the most virtuous and necessitarianism wins the day. Quite so. But notice that to get the necessitarian verdict here we need to presuppose something that seems very dubious. If the virtues function at all with respect to metaphysical claims the way they do with respect to scientific claims, then it seems very unlikely that parsimony always trumps simplicity. Otherwise I take it we should all be convinced that positrons are electrons going backwards in time: less simple, more parsimonious. On the other hand, if we can take no lessons about the virtues from the sciences, then I see no way to get a handle on them.

Thus, the contingentist should note, if we are to attain synthetic a priori 27 necessities by this method then there is all the danger in the world that our a priori reasoning does not track the objective virtues. Thus even if it turns out that $a$ priori reasoning leads us to converge on a particular CMA as being true in every world, we should be suspicious that this process really does track the objective virtues, and thus the truth. But insofar as we do think that our a priori reasoning yields true virtue, either because we are optimistic about our a priori reasoning, or because we have a deflationary view such as those presented as options two and three, it is by no means a foregone conclusion that this process will lead us to converge on a single CMA that is more virtuous in every world. Insofar as we think that this reasoning is good, we might well think that it could equally lead us to be contingentists about these metaphysical claims.

\section{Knowledge in a contingentist world}

Perhaps though, there are other reasons to be a necessitarian. One might worry that contingentism raises the prospect of rampant metaphysical scepticism such that we could never have any reason to think that the metaphysics of the actual world was

\footnotetext{
${ }^{30}$ For a discussion of some of these issues see Horgan (2000 and forthcoming).

${ }^{31}$ A referee made this suggestion.
} 
this way rather than that. Since we can have such reasons, contingentism must be false. To sum it up, necessitarianism is the only view consistent with a decent epistemology.

\subsection{Qualitatively indistinguishable worlds and other sceptical worries}

Suppose contingentism is true. Then there is a pair of qualitatively indistinguishable worlds, $w$ and $w^{\prime}$, such that in $w$ nihilistic monism is true, and in $w^{\prime}$ universalistic pluralism is true. Then the metaphysical facts of fundamentality and ontology fail to supervene on the qualitative facts. This renders metaphysical facts epistemically inaccessible since we have access only to the qualitative facts and the facts that supervene on those facts. So we could never know which CMA is actually true. This is absurd, so contingentism is absurd.

Notice first that there is all the difference in the world between pointing out that being committed to contingentism might lead to epistemological problems, and concluding that contingentism is false on that basis. On those grounds we should conclude that there are no worlds in which there are brains in a vat who think thoughts just like ours, or worlds that are subjectively just like this one but where agents are systematically misled.

Having said that, contingentists might deny the existence of these qualitatively indistinguishable worlds by holding that the relevant metaphysical facts do supervene on qualitative facts. For instance, as we will see in the following section, it might be that we have reason to hold that monism is true at gunk worlds, and pluralism is true at non-gunk worlds. So perhaps fundamentality facts supervene on facts about whether a world is infinitely divisible into parts.

The other option is to deny that the existence of this pair of words is problematic - or at least to deny that the necessitarian view is epistemically superior. The necessitarian holds that whichever CMA is true, it is true in all worlds, regardless of which qualitative facts hold. The metaphysical facts supervene on the qualitative facts, but they do so in an entirely trivial manner. Given necessitarianism, we know that for any worlds $w_{1}$ and $w_{2}$, if $w_{1}$ and $w_{2}$ differ with respect to the metaphysical facts, then they differ with respect to the qualitative facts. ${ }^{32}$ This is trivially true, because, given necessitarianism, there are no worlds that differ with respect to the metaphysical facts. To put it another way, any necessarily true claim is entailed by the qualitative facts. So if monism is necessarily true, the sense in which it is entailed by the qualitative facts is no more informative than the sense

${ }^{32}$ Technically, A properties globally supervene on B properties iff for any worlds $w_{1}$ and $w_{2}$, if $w_{1}$ and $w_{2}$ have exactly the same world-wide pattern of distribution of $B$-properties, then they have exactly the same world-wide pattern of distribution of $A$-properties. The converse of this is sometimes known as determination. Then A properties are determined by B properties iff for any worlds $w_{1}$ and $w_{2}$, if $w_{1}$ and $w_{2}$ differ with respect to their distribution of A properties, then they differ with respect to their distribution of B properties. 
in which the mathematical truths are entailed by the qualitative facts. Nothing about the nature of a world tells us which CMA is true, because there is no difference in the qualitative facts that could produce a difference in the metaphysical facts. So we can no more ascertain which (necessary) CMA is true by examining the qualitative features of the actual world than we can ascertain which (contingent) CMA is true by examining those features. On this score, contingentists and necessitarians are in the same boat.

\subsection{A priori conditionals, a posteriori knowledge}

Now, the necessitarian might maintain that she has a better account of the epistemic accessibility of metaphysical truths, because she can claim that we arrive at metaphysical knowledge through a priori reasoning. But the contingentist is not barred from a priori reasoning. The problem, I take it, is that once we allow that metaphysical truths are contingent, we allow that there are agents in exactly the same epistemic position as us, with the same a priori reasons, who are wrong in their metaphysical conclusions because in their world some other metaphysical claim is true.

As I said previously, I do not see that we can draw metaphysical conclusions from epistemological concerns or lack thereof. Still, the contingentist needs to say more. In general the worry here is how a priori reasoning can tell us about contingent features of our world given that there is no plausible account of the contingent a priori.$^{33} \mathrm{I}$ think there are a few options open to the contingentist. One option is to hold a deflationary view such as those discussed earlier, and claim that the CMAs are contingent truths because different CMAs will be the most virtuous in different worlds. Then agents have access to the same a priori reasons, but are differently located with respect to the a posteriori facts about their world, and thus agents in different worlds are not in the same epistemic situation at all. No epistemological problems then arise, since there is no gap between a theory's being the most virtuous and its being true. Given a deflationist presupposition, the contingentist and the necessitarian are in the same epistemic boat - they just disagree about whether the same CMA will turn out to be more virtuous in every world. The other possibility is that one embraces the non-deflationary account option one. This does open up epistemological worries, since there is reason to doubt that the results of ideal reflection track the real virtues. But that worry is the same for contingentists and necessitarians alike. If one assumes that ideal reflection is a good guide to the real virtues, then the debate between contingentists and necessitarians is, again, a debate about whether ideal reflection tells us that the

${ }^{33}$ Or at least, the only accounts of the contingent a priori on offer are clearly not of the sort that would generalize to first-order claims in metaphysics, such as the accounts of Kripke 42 (1980) and Donnellan (1977). 
same CMA is more virtuous in every world. If one does not assume any such thing, then it is hard to see how one would come by metaphysical truths whether one was a necessitarian or a contingentist. Given either of these two strategies that see metaphysical truths as synthetic a priori, the contingentist is in no worse a position than the necessitarian.

The other contingentist option is to hold that metaphysical truths are known $a$ posteriori. Prima facie that seems to push contingentists in one of two unpalatable directions: towards what I will call scientism, on the one hand, or anti-scientism, on the other. To embrace scientism is to accept that a posteriori investigation is best understood in terms of scientific methodology. So one way or another, metaphysics will be dissolved into the natural sciences, either by scientific inquiry discovering the relevant truth-makers of the contingent claims, or by discovering that there are no such truth-makers and hence that metaphysical claims are vacuous. Neither of these possibilities bodes well.

Alternatively, the contingentist could embrace anti-scientism, which would be to accept that, although metaphysical claims are known a posteriori, scientific methodology is not the appropriate methodology. What, then, is? I tentatively make the following suggestion. Much of what metaphysicians are doing is a priori reasoning that yields necessary truths that are themselves conditional claims, where the antecedent of the conditional is contingent. For instance, it is an a priori conceptual truth that necessarily something is a tiger just in case it has features $F_{1} \ldots F_{n}$, and has causal ancestry $C$ (let us suppose). But it is a contingent $a$ posteriori matter whether there are any tigers, since there might actually be nothing with those features and that ancestry. Suppose then, that there was an $a$ priori necessary conditional claims of the form, "if $w$ has feature $F$, then $\mathrm{CMA}_{\mathrm{i}}$ is true in $w^{\prime}$. Then if it is a contingent matter whether or not some $w$ has $F$, it will be contingent whether $\mathrm{CMA}_{\mathrm{i}}$ is true in that world. How one sees this view depends on how one views these conditionals. One option is that they are synthetic a priori claims. In that case, these conditional claims add meat to the claims of the contingentists we have already met, who appeal to a priori reasoning to show that different CMAs are true in different worlds because different CMAs are more virtuous in different worlds. The conditionals, in effect, distil some of this information about virtue into a conditional with a contingent antecedent. Given that these conditionals have contingent antecedents, however, if it is an a posteriori matter whether an antecedent is true in a particular world, then it will be an $a$ posteriori matter to determine which CMA is true at that world. All we can determine a priori is the set of conditionals, not which world we are in.

Alternatively, we might think that these conditionals are conceptual truths, therefore allowing us to embrace the view that whatever is correctly conceivable is possible. We cannot correctly conceive that the conditionals are false. We can correctly conceive that different CMAs are possible, and thus, they are possible. 29 
But since correct conceivability involves specifying all the relevant features of a world, it will not be possible to correctly conceive both that the antecedent of those conditionals is true at a world, and the consequent false. Thus we will be able to 30 determine, in conjunction with these conceptual truths, which metaphysical truths hold at which world, although that discovery will itself be a posteriori.

Are there such conditional claims? The next section considers two arguments purporting to show the necessary modal status of the CMAs. It will be useful to examine these arguments and to see why, instead, they should push us towards contingentism. In the process we can see how we might come up with conditional claims of the above form. It will then be a further question whether these conditionals are best thought of as conceptual truths or as synthetic a priori claims, or whether we find some of both.

\subsubsection{Conditional claims: a gunky example}

A particular is composed of gunk just in case for every part of that particular, that part has a further proper part. Call a world entirely composed of gunk a gunk world. It has been claimed that the possibility of a gunk world provides an argument for monism (Schaffer, unpublished). In a world that is infinitely divisible into parts, there are no simples. There is no 'bottom level' of entities that can be the fundamental ones from which everything else is composed. In a gunk world pluralism is false, and, arguably, monism is true: the world is fundamental. ${ }^{34}$ Call this the argument from gunk. As I see it, the argument from gunk bolsters the claim that the CMAs are contingent theses. For simplicity, and I will not argue the case here, let us suppose that restricted composition is necessarily false because any non-vague restriction on composition will be arbitrary or ad hoc (this is grist to the necessitarian mill since it removes one possible source of contingency). Then we can offer the following argument:

(1) Restrictivist monism is necessarily false (the arguments from vagueness and non-arbitrariness).

(2) In a gunk world, pluralism is false (argument from gunk).

(3) In a gunk world, nihilism is false (from the definition of gunk).

(4) Therefore in a gunk world restrictivist monism and restrictivist pluralism and universalist pluralism and nihilism pluralism and nihilist monism are false (by (1)-(3)).

(5) At any world $w$, either universalist pluralism or nihilism pluralism or nihilist monism or universalist monism is true.

(6) Therefore in a gunk world, universalist monism is true.

\footnotetext{
${ }^{34}$ Whether this is so is debatable. For more on this see Cameron (2007).
} 
The controversial claim here is surely (5), which says, in effect, that the four CMAs mentioned in this paper exhaust the metaphysical possibilities if contingentism is true. Or, to put it another way, they are the only epistemically possible metaphysical theories if necessitarianism is true. But perhaps we can correctly conceive of a gunk world in which, say, some mid-level particulars are fundamental, and these unrestrictedly compose and unrestrictedly decompose into further particulars. Then restricted composition is false, as per (1). Nihilism is false, as per (3), and pluralism is false, as per (2). But monism is also false, since it is the mid-level particulars that are fundamental. If correct conceivability is a guide to possibility and this view is correctly conceivable, then (6) is false: not all gunk worlds are universalist monist worlds. It might be part of our concept of fundamentality that it cannot be arbitrary or ad hoc which particulars are fundamental. It is no accident that for the pluralist, the fundamental things are the ultimate simples, and for the monist, the fundamental thing is the whole itself. The notion that some other level of particular could be fundamental, and there exist both composition and decomposition relations, might be a conceptual error. It is unclear how plausible this contention is. At any rate, the possibility of this alternative CMA is not only a problem for contingentists who think that correct conceivability is a guide to possibility. Those who think that metaphysical truths are synthetic $a$ priori truths can only rule out the possibility of such a view if they think there is no world in which that CMA is the most virtuous. Perhaps we can determine this a priori. Or perhaps we can show that such a view is conceptually incoherent. If not, the conditional claim that we are trying to attain cannot be of the form, 'if $w$ is a gunk world, then universalist monism is true in $w^{\prime}$.

That is not to say that there couldn't be a different conditional that tells us that if $w$ is a gunk world then either $w$ is a universalist monist world or ..., where we need to fill in these ellipses by amending the new gunk argument. Even if this particular argument only told us that if $w$ is a gunk world then either $x$ or $y$ or $z$ is true in $w$, this would be useful for the contingentist since other a priori reflection yielding other conditionals might ultimately allow us to determine that only one CMA can be true in $w$. To simplify matters, let us suppose that the new gunk argument is sound, whilst keeping in the back our minds that, even if it is not, an amended form of the argument will yield a different conditional that need not be useless to the contingentist.

(6) is an a priori necessary truth. Since it is surely a contingent matter whether a world is a gunk world or not, prima facie the argument ought to push us towards contingentism about universalist monism. The necessitarian might, however, add in some premises to try to get out a necessitarian conclusion. She might add in (7).

(7) There is a possible gunk world.

The contingentist too endorses (7). But Schaffer thinks that the gunk argument plus (7), plus what he calls the generality constraint will yield a necessitarian 
conclusion. According to the generality constraint, the metaphysically basic entities must have a form that fits all possibilities. In other words, there are no ways the world could be that are not ways the base could be (Schaffer, unpublished, pp. 9-10). Let us add the generality constraint to the above argument to create the new gunk argument.

(8) The metaphysically fundamental entities must have a form that fits all possibilities.

If gunk worlds are possible, then the basic entities must have a form that is consistent with those entities existing in a gunk world. In a gunk world, the world is fundamental - it is the basic entity. Hence the new gunk argument entails that our account of the basic entities must be one according to which the world is fundamental. Thus the conclusion to the new gunk argument is that monism is necessarily true. Notice that even if we accept the new gunk argument, it is not sufficient to establish necessitarianism, since it establishes Claim 1 (that monism is necessarily true) but not Claim 2. It is consistent with the new gunk argument that universalism is true in some worlds (the gunk worlds) and nihilism in others (the non-gunk worlds), and hence that universalist monism and nihilist monism are contingent views.

Setting this aside though, is there any reason to believe (6)? Schaffer gives one argument that does not presuppose necessitarianism, namely that if (6) did not hold this would entail a spurious multiplication of possibilities. What is so bad 31 about positing spurious possibilities? Well, it flouts the desideratum of ontological parsimony. We might not be worried about positing additional possible worlds, since possible worlds are cheap unless one is a modal realist. But in positing additional possible worlds we posit additional alien properties and relations, and this ontological profligacy is objectionable.

Notice that this argument presupposes either that modal ersatzists will eschew positing impossible worlds, or that, if they do posit them, they will be less 32 ontologically committed to the entities in those worlds. For if one thinks of the ontology of possible and impossible worlds as on a par, then it makes no difference, in terms of ontological parsimony, whether one takes more or fewer worlds to be possible. But even setting aside the issue of impossible worlds, ontological parsimony only requires limiting ontology to that which is explanatorily required. The contingentist precisely does not think it is a spurious multiplication. She thinks she has good reason to reject necessitarianism, in which case those worlds represent genuine possibilities. But if we have no independent reason to endorse (8), we have no reason to think that the new gunk argument entails the necessary truth of monism.

Instead, the new gunk argument minus (8) supports contingentism. If gunk worlds are possible, then, by the new gunk argument, we have reason to think that in a gunk world monism is true. But what should we think about non-gunk worlds? Plausibly, we can mount an argument analogous to the gunk argument. In a 
non-gunk world, not every part has a further part. This entails that some particulars are simple. From this, we can get the following non-gunk argument.

(1) Restrictivist pluralism is necessarily false (the arguments from vagueness and non-arbitrariness).

(2) In a non-gunk world there are simples.

(3) Nihilistic monism is false in any world with simples (from the definition of nihilist monism).

(4) In any world $w$, either universalist pluralism or nihilism pluralism or 33 nihilist monism or universalist monism is true.

A non-gunk world is a world in which either nihilistic pluralism, or 34 universalist pluralism, or universalist monism is true.

Again, this argument includes the controversial claim (4), which, for current purposes, we are accepting. The non-gunk argument does not tell us which CMA is true in a non-gunk world. Once we have a whole set of conditionals, however, we might be able to determine at which worlds which CMA is true. At the very least, we might be able to know which CMA is true in some worlds, and narrow it down substantially in others. The new gunk argument provides the kind of conditional claim that contingentists are looking for. It gives us reason to endorse the conditional claim, 'if $w$ is a gunk world, then universalist monism is true in $w$ '. Or perhaps, if premise (5) of the new gunk argument is false, that argument gives us a conditional more like that of the non-gunk argument. Either way, the resulting conditional is necessary a priori. Is it a conceptual truth?

I think it is plausible that it is a conceptual truth. If (6) is true, then we cannot correctly conceive of a gunk world in which universalist monism is false. For what it is to be a gunk world is to be a world where nihilism is false, and if it is a conceptual truth that the four CMAs are the only possible metaphysical views, then once we specify the nature of a gunk world we will find the conditional to be conceptually necessary. On the other hand, if (5) is false, then the new gunk argument will yield a different conclusion that includes more views in the consequent: but plausibly that conditional, too, will be a conceptual truth about gunk worlds. It follows from the nature of a gunk world that it is either a world in which $x, y$ or $z$ is true at that world. That conditional, like the conditional we reach in the non-gunk argument, is a more complex one. Each of these is a truth we could only come to after a good deal of reflection. But (given that 4 is a conceptual truth) it does seem to follow from the concept of a non-gunk world that that world will be one in which either nihilistic pluralism, universalist pluralism, or universalism monism is true. Having correctly conceived of a non-gunk world, one could not, in fact, conceive that that was a world in which nihilistic monism was true. That is conceptually incoherent. Given that we make further discoveries about other conditionals, we might find a narrower conceptual claim that links a non-gunk 
world with a particular CMA. That remains to be seen. But even with these two conditionals we can go some way towards a contingentist epistemology.

In general, then, we first engage in a priori reflection that yields conditional claims. Since the antecedent is contingent, we require a posteriori facts to determine which world we are in. Nevertheless, the threat of scepticism does not arise, since to the extent that we can be sure that ours is, say, a gunk world we can be sure which CMA is true. So although agents in every world might be in the same a priori situation, all coming not know the very same sets of conditionals, they will 35 draw different conclusions about their own world, depending on which of the antecedents of various conditionals they take to be true.

Consider another example.

\subsubsection{Conditional claims and quantum mechanics}

Schaffer marshals another argument for monism, what I call the argument from quantum mechanics. Given the phenomenon of quantum entanglement, the causal story that physics tells is more likely to be holistic than local. Monism is more consistent with a holistic causal story than is pluralism, and therefore monism is more consistent than pluralism with what we currently know about quantum mechanics (Schaffer, unpublished, pp. 21-25). Let us grant the still speculative conclusion that the truths of quantum mechanics militate in favour of a monistic metaphysics. ${ }^{35}$ Then we have reason to conclude that in any world governed by the laws of quantum mechanics, monism is true.

This reasoning suggests that monism is true in worlds where the quantum mechanical laws hold. Given that we have no reason to appeal to the generality principle, if there are worlds with non-actual laws, as is plausibly the case, then in those worlds we might have no reason to think that monism is true. More particularly, there could be non-actual laws that militate in favour of pluralism. In such worlds the physics is very local, say, and not at all holistic. In those worlds we have reason to think that pluralism is true.

Now, whatever exactly we make of these arguments, it is fairly clear that the conditional claims we get will not be conceptual truths. We have a priori reasons to think that worlds with quantum mechanics are monistic, and that worlds with other very different laws are pluralistic. In this case the conditionals are synthetic a priori.

Whether all such conditionals are synthetic a priori or some are conceptual truths is open to debate. In some sense it does not matter, from the point of view of the epistemology of the contingentist. So long as she can come up with these conditionals, she can have good reason to think that certain worlds are ones with

${ }^{35}$ Schaffer nowhere suggests that pluralism is inconsistent with our best physical theory, merely that, given the nature of the physical theory, it accords better with monism. 
certain metaphysical truths, and other worlds with different truths. If all the 36 conditionals are synthetic a priori, then her epistemic position is exactly that of the necessitarian who also thinks that the relevant metaphysical claims are synthetic $a$ priori. Ultimately both of these views have to deny that correct conceivability is always a good guide to what is possible. Instead she embraces the synthetic $a$ priori: the epistemology is in both cases the same; the disagreement is merely about which a priori claims are necessary. To the extent that the contingentist embraces these conditional claims as conceptual truths, she is in a position to hold that correct conceivability is a good guide to possibility, and that what correct conceivability tells us is that contingentism is true, but, given a sufficient array of conditionals, we can still know which metaphysical claims are true in which worlds by coming to know at which worlds the relevant antecedents of such conditionals are true.

\section{Conclusion}

I have tried to show that contingentism is no more epistemically problematic than necessitarianism. We can have reason to think, of some metaphysical claim, that it is contingently true. In particular, I think that the CMAs are views of this sort. The necessitarian about the CMAs needs to show that either monism or pluralism is necessarily true, and that if monism is necessarily true, then the correct answer to the special decomposition question is a necessary truth, and if pluralism is necessarily true, then the correct answer to the special composition question is a necessary truth. I hope that this paper has given us reason to think that the necessitarian fails on both counts. Whether we think of metaphysical claims as conceptual truths or as a priori synthetic truths, we have no good reason to think that the CMAs are modally necessary. At the very least, if the necessitarian thinks we do then the emphasis is on her to show us why.

Moreover, it may be that contingentism has other benefits. Everyone needs an account of the hyperintensional, contingentists included. Since opposing metaphysical views like the CMAs are pretty clearly not conceptually incoherent, the necessitarian needs a story about the content of necessarily false metaphysical claims. She had better have a way of making sense of conditionals with necessarily false antecedents. Likewise, I noted that some of the a priori necessary conditional claims the contingentist will appeal to look like conceptual truths, whereas others look less so. So the contingentist will need to say something about the content of the negation of these necessarily true conditionals. But it may be, and here is a tentative suggestion only, that the contingentist does not need such a robust account of the hyperintensional as does the necessitarian. Those who are drawn to some kind of modal realism - the view that there are irreducible modal truths that outstrip the truths about our world (not concrete modal realism) - as opposed to 
ersatzism might embrace ersatzism about impossible worlds as a way of making sense of hyperintensional content. The idea, I take it, is that one can build one's ersatzist hyperintensional content out of one's realist intensional content.

Consider the, let us suppose, necessarily true conditional that in gunk worlds monism is true. The conditional 'there is a gunk world in which monism is false' is necessarily false, and thus even the contingentist will need to appeal to some ersatz impossible world. But she, as distinct from the necessitarian, has additional 37 resources in dealing with conditionals like this, since for her there are possible gunk worlds and possible worlds in which monism is false. Indeed, there are possible worlds corresponding to each CMA. So she has a lot of background intensional content upon which to build her hyperintensional content, as it were. Since the necessitarian has much less intensional content, one might, therefore, suppose that she will need a more robust account of hyperintensional content. At least, it is worth contingentists thinking about whether they can parlay their additional plethora of possible worlds into an advantage when it comes to the hyperintensional. That might truly push one towards contingentism.*

\section{REFERENCES}

Armstrong, D. and Heathcote, A. 1991, 'Causes and Laws' Nous 25, pp. 63-73.

Block, N and Stalnaker, R. 1999, 'Conceptual Analysis, Dualism and the Explanatory Gap', Philosophical Review 108, pp. 1-46.

Cameron, R. 2007, 'Turtles all the Way Down: Regress, Priority and Fundamentality', Philosophical Quarterly 58, pp. 1-14.

Cameron, R. forthcoming, 'The Contingency of Composition.' Philosophical Studies.

CARnAP, R. 1932, 'The Elimination of Metaphysics through Logical Analysis of Language', in: A.J. Ayer, ed., Language, Truth and logic 1946, Harmondsworth: Penguin.

Chalmers, D. 1996, The Conscious Mind, Oxford: Oxford University Press.

Chalmers, D. 2004, 'Epistemic Two Dimensional Semantics', Philosophical Studies 118, pp. 153226.

Donnellan, K. 1977, 'The Contingent A Priori and Rigid Designators', Midwest Studies in Philoso- 40 phy 2.

FIELD, H. 1993, 'The Conceptual Contingency of Mathematical Objects' Mind 102, pp. 285-299.

Hale, B. and Wright, C. 1992, 'Nominalism and the Contingency of Abstract Objects', The Journal of Philosophy 89, pp. 111-135.

Heller, M. 1990, The Ontology of Physical Objects: Four Dimensional Hunks of Matter, Cambridge: Cambridge University Press.

Hirsch, E. 2002, 'Quantifier Variance and Realism', Philosophical Issues, 12 Realism and Relativism, pp. 51-73.

Horgan, T. and Potrč, M. 2000, 'Blobjectivism and Indirect Correspondence', Facta Philosophica 2 , pp. 249-270.

Horgan, T. and Potrč, M. (forthcoming) Austere Realism. Cambridge, MA: MIT Press.

JaCkson, F. 1998, From Metaphysics to Ethics: A Defence of Conceptual Analysis, Oxford: Oxford University Press.

* With thanks to Terry Horgan for helpful discussion of these issues, and to David Braddon-Mitchell, Luca Moretti and Jonathan Schaffer. 
JOBNAME: No Job Name PAGE: 27 SESS: 8 OUTPUT: Thu Feb 12 16:44:34 2009 SUM: $123 E F 262$

/v2503/blackwell/journals/dltc_v0_i0/dltc_1181

Defending Contingentism in Metaphysics

JACKSON, F. 2004, 'Why we need A-intensions', Philosophical Studies 118, pp. 257-277

KrIPKE, S. 1972, Naming and Necessity, Cambridge, MA: Harvard University Press.

Lewis, D. 1986, On the Plurality of Worlds, New York: Blackwell Press.

LewIS, D. 1988, 'Vague Identity: Evans Misunderstood', Analysis 48, pp. 128-130.

LEwIS, D. 1994, 'Humean Supervenience Debugged' Mind 103, pp. 473-490.

Macbride, F. 2006, Identity and Modality, Oxford: Oxford University Press.

Mccall, S. 1994, A Model of the Universe: Space-Time, Probability, and Decision, Oxford: Clarendon Press.

Markosian, N. 2007, 'Restricted Composition', in: D. Zimmerman, T. Sider and J. Hawthorne, eds, Contemporary Debates in Metaphysics, Oxford: Oxford University Press.

Merricks, T. 2001, Objects and Persons, Oxford: Oxford University Press.

Miller, K. 2005, 'What is Metaphysical Equivalence?' Philosophical Papers 34, pp. 35-74.

PARSONS, J. 2006, ‘Conceptual conservatism and contingent composition', Unpublished.

Putnam, H. 1988, 'After Metaphysics, What?' in: D. Zimmerman and P. van Inwagen, eds, Metaphysics:The Big Questions, Oxford: Basil Blackwell, pp. 388-392.

Putnam, H. 1987, 'Truth and Convention', in: D. Zimmerman and P. van Inwagen, eds, Metaphysics: The Big Questions, Oxford: Basil Blackwell, pp. 392-398.

Quine, W.V.O. 1963, 'Identity, Ostension and Hypostasis' in his From a Logical Point of View, Harper 43 and Row, pp. 65-79.

Rosen, G. 2006, 'The Limits of Contingency', in: F. McBride, ed., Identity and Modality, Oxford: Oxford University Press, pp. 13-38.

SCHAFFER, J. (unpublished) 'Monism: the Priority of the Whole'.

Schaffer, J. 2005, 'Quiddistic Knowledge', Philosophical Studies 123, pp. 1-32.

SCHAFFER, J. 2007, 'For (Priority) Monism: Reply to Sider', Analysis 67.

SIDER, T. 2001, Four-dimensionalism: An Ontology of Persistence and Time, Oxford: Oxford University Press.

Sider, T. 2003, 'Against Vague Existence', Philosophical Studies 114, pp. 135-146.

SIDER 2007, 'Against Monism', Analysis 67.

Unger, P. 1979, 'I Do Not Exist', in: G. F. Macdonald, ed, Perception and Identity, London: Macmillan Press.

VAN InWAGEN, P. 1990, Material Beings, New York: Cornell University Press.

Williams, J.R.G. 2006, 'Illusions of Gunk', Philosophical Perspectives 20, pp. 493-513.

YabLo, S. 1998, 'Does Ontology Rest on a Mistake?' Proceedings of the Aristotelan Society supplementary volume 72, pp. 229-262. 


\begin{tabular}{|l|l|}
\hline \multicolumn{2}{|c|}{ SNP Best-set Typesetter Ltd. } \\
\hline Journal Code: DLTC & Proofreader: Elsie \\
\hline Article No: 1181 & Delivery date: 12 February 2009 \\
\hline Page Extent: 27 & \\
\hline
\end{tabular}

\section{AUTHOR QUERY FORM}

Dear Author

During the preparation of your manuscript, the questions listed below have arisen. Please answer all the queries (marking any other corrections on the proof enclosed) and return this form with your proofs.

\begin{tabular}{|c|c|c|}
\hline Query no. & Query & Reply \\
\hline q1 & AUTHOR: Please provide a full postal address & \\
\hline q2 & $\begin{array}{l}\text { AUTHOR: Please note that it is journal style is } \\
\text { to have references in the text rather than as } \\
\text { footnotes - please check the changes. Please } \\
\text { add Horgan } 2000 \text { to the list. }\end{array}$ & \\
\hline q3 & $\begin{array}{l}\text { AUTHOR: Is the change from 'where it is, } \\
\text { often tacitly assumed' OK? }\end{array}$ & \\
\hline q4 & $\begin{array}{l}\text { AUTHOR: Please check the sense of } \\
\text { 'non-fundamental compose entities' }\end{array}$ & \\
\hline q5 & $\begin{array}{l}\text { AUTHOR: Please check the sense of 'at } \\
\text { sub-regions of the world as } \\
\text { [are?]non-fundamental }{ }^{1} \text { proper parts of the } \\
\text { world' }\end{array}$ & \\
\hline q6 & $\begin{array}{l}\text { AUTHOR: Please check the sense of 'those } \\
\text { particulars as [is?] non-fundamental }\end{array}$ & \\
\hline q7 & $\begin{array}{l}\text { AUTHOR: Is the addition of commas OK in } \\
\text { 'Then, for any world } w \text { such that we can } \\
\text { decompose } w \text { into multiple disjoint regions } \\
\text { each of which is occupied by some } \\
\text { particular,'? }\end{array}$ & \\
\hline q8 & $\begin{array}{l}\text { AUTHOR: Please check the sense of the } \\
\text { footnote beginning 'Where a particular P } \\
\text { wholly' }\end{array}$ & \\
\hline q9 & $\begin{array}{l}\text { AUTHOR: Merricks (2000) has not been } \\
\text { included in the Reference List, please supply } \\
\text { full publication details. }\end{array}$ & \\
\hline
\end{tabular}




\begin{tabular}{|c|c|}
\hline q10 & $\begin{array}{l}\text { AUTHOR: The text has both 'in a world' and } \\
\text { 'at a world'. Do you want to make the } \\
\text { terminology consistent throughout? }\end{array}$ \\
\hline q11 & $\begin{array}{l}\text { AUTHOR: Do you mean e.g. 'and it is less } \\
\text { likely that this will be so'? }\end{array}$ \\
\hline q12 & $\begin{array}{l}\text { AUTHOR: Is the change from 'pluralism is } \\
\text { necessary true' OK? }\end{array}$ \\
\hline q13 & $\begin{array}{l}\text { AUTHOR: [footnote] Do you mean 'This } \\
\text { presupposes that monism and pluralism are } \\
\text { exhaustive'? }\end{array}$ \\
\hline q14 & $\begin{array}{l}\text { AUTHOR: Is the change from 'implausible } \\
\text { that we should conclude that in a } \\
\text { counterfactual world } w \text { in which there exist } \\
\text { simples but only some mereological } \\
\text { 'composites', that we should conclude not } \\
\text { that' OK? }\end{array}$ \\
\hline q15 & $\begin{array}{l}\text { AUTHOR: Is the change from 'According to } \\
\text { Rosen would put it' OK? }\end{array}$ \\
\hline q16 & $\begin{array}{l}\text { AUTHOR: Is the change from 'we cannot } \\
\text { correct conceive as being false, what is' OK? }\end{array}$ \\
\hline q17 & $\begin{array}{l}\text { AUTHOR: Please clarify what 'they' refers to } \\
\text { in 'because they appeal to the existence of } \\
\text { facts' }\end{array}$ \\
\hline q18 & $\begin{array}{l}\text { AUTHOR: Is the change from 'there is } \\
\text { genuine a danger' OK? }\end{array}$ \\
\hline q19 & $\begin{array}{l}\text { AUTHOR: Do you mean 'is more consistent } \\
\text { with recent views/methods of proponents'? }\end{array}$ \\
\hline q20 & $\begin{array}{l}\text { AUTHOR: Is the change from 'competitor } \\
\text { claims incoherent' OK? }\end{array}$ \\
\hline $\mathrm{q} 21$ & $\begin{array}{l}\text { AUTHOR: Could the text be changed to 'why } \\
\text { this far into our investigation'? }\end{array}$ \\
\hline $\mathrm{q} 22$ & $\begin{array}{l}\text { AUTHOR: Is 'psychologistic' a recognized } \\
\text { term? }\end{array}$ \\
\hline $\mathrm{q} 23$ & $\begin{array}{l}\text { AUTHOR: Is the change from 'necessary, } \\
\text { although had' OK? }\end{array}$ \\
\hline q24 & $\begin{array}{l}\text { AUTHOR: can 'either' be deleted from 'not } \\
\text { really genuine either.'? }\end{array}$ \\
\hline
\end{tabular}




\begin{tabular}{|c|c|}
\hline q25 & $\begin{array}{l}\text { AUTHOR: [footnote] Is there an update for } \\
\text { Cameron (forthcoming)? Is the sense of 'This } \\
\text { suggestion differs' OK? [differs from what?] }\end{array}$ \\
\hline q26 & $\begin{array}{l}\text { AUTHOR: [footnote]Is there an update for the } \\
\text { forthcoming paper? }\end{array}$ \\
\hline q27 & $\begin{array}{l}\text { AUTHOR: Is the change from 'if we are attain } \\
\text { synthetic' OK? }\end{array}$ \\
\hline q28 & $\begin{array}{l}\text { AUTHOR: Please supply the initials for Sider } \\
\text { in Sider, } 2007\end{array}$ \\
\hline q29 & $\begin{array}{l}\text { AUTHOR: Is the sense of 'and thus, they are } \\
\text { possible' OK? }\end{array}$ \\
\hline q30 & $\begin{array}{l}\text { AUTHOR: Could the text be changed to 'and } \\
\text { that the consequent is false'? }\end{array}$ \\
\hline q31 & $\begin{array}{l}\text { Author; Is the change from 'necessitarianism, } \\
\text { that if (6) did not hold' OK? }\end{array}$ \\
\hline q32 & $\begin{array}{l}\text { AUTHOR: is the change from 'that modal } \\
\text { ersatzists will either eschew positing } \\
\text { impossible worlds, or that if they do posit } \\
\text { them, they' OK? }\end{array}$ \\
\hline q33 & $\begin{array}{l}\text { AUTHOR: Is the change from '(4) It any } \\
\text { world } w \text {, OK? }\end{array}$ \\
\hline q34 & $\begin{array}{l}\text { AUTHOR: Is the change from 'A non-gunk } \\
\text { world is either a world in which nihilistic } \\
\text { pluralism' OK? }\end{array}$ \\
\hline q35 & $\begin{array}{l}\text { AUTHOR: Please check the sense of 'all } \\
\text { coming not know the very same sets of } \\
\text { conditionals' }\end{array}$ \\
\hline q36 & $\begin{array}{l}\text { AUTHOR: Please check the sense of 'and } \\
\text { other worlds with different truths' }\end{array}$ \\
\hline q37 & $\begin{array}{l}\text { AUTHOR: is the change from 'in distinction } \\
\text { to the necessitarian' OK? }\end{array}$ \\
\hline q38 & $\begin{array}{l}\text { AUTHOR: Is there an update for CAMERON, R. } \\
\text { forthcoming }\end{array}$ \\
\hline q39 & AUTHOR: Please clarify the year 1932/1946 \\
\hline $\mathrm{q} 40$ & $\begin{array}{l}\text { AUTHOR: Is thee a page range for } \\
\text { DonNELLAN, K. 1977,? }\end{array}$ \\
\hline
\end{tabular}




\begin{tabular}{|l|l|l|}
\hline $\mathrm{q} 41$ & $\begin{array}{l}\text { AUTHOR: Is there an update for HoRGAN, T. } \\
\text { and PoTRČ, M. (forthcoming)? }\end{array}$ & \\
\hline $\mathrm{q} 42$ & $\begin{array}{l}\text { AUTHOR: Kripke (1980) has not been } \\
\text { included in the Reference List, please supply } \\
\text { full publication details. }\end{array}$ & \\
\hline $\mathrm{q} 43$ & $\begin{array}{l}\text { AUTHOR: Please provide a location for } \\
\text { Harper and Row }\end{array}$ & \\
\hline $\mathrm{q} 44$ & $\begin{array}{l}\text { AUTHOR: Please supply a page range for } \\
\text { SCHAFFER, J. 2007 }\end{array}$ & \\
\hline $\mathrm{q} 45$ & $\begin{array}{l}\text { AUTHOR: Sider, 2003 has not been cited in } \\
\text { the text. Please indicate where it should be } \\
\text { cited; or delete from the Reference List. }\end{array}$ & \\
\hline $\mathrm{q} 46$ & $\begin{array}{l}\text { AUTHOR: Please provide a page range for } \\
\text { SiDER 2007 }\end{array}$ & \\
\hline $\mathrm{q} 47$ & $\begin{array}{l}\text { AUTHOR: Please provide a page range for } \\
\text { Unger, P. 1979 }\end{array}$ & \\
\hline
\end{tabular}




\section{Please correct and return this set}

Please use the proof correction marks shown below for all alterations and corrections. If you wish to return your proof by fax you should ensure that all amendments are written clearly in dark ink and are made well within the page margins.

\begin{tabular}{|c|c|c|}
\hline Instruction to printer & Textual mark & Marginal mark \\
\hline Leave unchanged & ... under matter to remain & ( ) \\
\hline $\begin{array}{l}\text { Insert in text the matter } \\
\text { indicated in the margin }\end{array}$ & $\Lambda$ & $\begin{array}{l}\text { New matter followed by } \\
h \text { or } h \otimes\end{array}$ \\
\hline Delete & $\begin{array}{l}\text { I through single character, rule or underline } \\
\text { or }\end{array}$ & $\sigma$ or $\sigma / \otimes$ \\
\hline $\begin{array}{l}\text { Substitute character or } \\
\text { substitute part of one or } \\
\text { more word(s) }\end{array}$ & / through letter or & $\begin{array}{l}\text { new character / or } \\
\text { new characters / }\end{array}$ \\
\hline Change to italics & — under matter to be changed & $\leftarrow$ \\
\hline Change to capitals & $\equiv$ under matter to be changed & $\equiv$ \\
\hline Change to small capitals & $=$ under matter to be changed & $=$ \\
\hline Change to bold type & $\sim$ under matter to be changed & $\sim$ \\
\hline Change to bold italic & $\bar{\sim}$ under matter to be changed & $\widehat{\omega}$ \\
\hline Change to lower case & Encircle matter to be changed & $\not$ \\
\hline Change italic to upright type & (As above) & \\
\hline Change bold to non-bold type & (As above) & \\
\hline Insert 'superior' character & $\begin{array}{l}\text { I through character or } \\
K \text { where required }\end{array}$ & $\begin{array}{l}y^{\prime} \text { or } y \\
\text { under character } \\
\text { e.g. } y^{2} \text { or } y^{2}\end{array}$ \\
\hline Insert 'inferior' character & (As above) & $\begin{array}{l}\text { L } \\
\text { over character } \\
\text { e.g. } \hat{\imath}\end{array}$ \\
\hline Insert full stop & (As above) & $\odot$ \\
\hline Insert comma & (As above) & , \\
\hline Insert single quotation marks & (As above) & $\begin{array}{l}\dot{y} \text { or } \dot{X} \text { and/or } \\
\dot{y} \text { or } \dot{X}\end{array}$ \\
\hline Insert double quotation marks & (As above) & $\begin{array}{l}\dddot{y} \text { or } \ddot{x} \text { and/or } \\
\ddot{y} \text { or } \ddot{x}\end{array}$ \\
\hline Insert hyphen & (As above) & $1-1$ \\
\hline Start new paragraph & $\digamma$ & 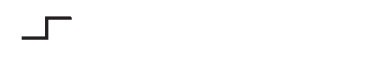 \\
\hline No new paragraph & $\infty$ & $\omega$ \\
\hline Transpose & $\sqcup$ & ᄃ \\
\hline Close up & linking $\bigcirc$ characters & \\
\hline $\begin{array}{l}\text { Insert or substitute space } \\
\text { between characters or words }\end{array}$ & $\begin{array}{l}\text { I through character or } \\
\Lambda \text { where required }\end{array}$ & \\
\hline $\begin{array}{l}\text { Reduce space between } \\
\text { characters or words }\end{array}$ & $\begin{array}{l}\text { between characters or } \\
\text { words affected }\end{array}$ & $\uparrow$ \\
\hline
\end{tabular}

